\title{
Physiologic Significance of Epigenetic Regulation of Thyroid Hormone Target Gene Expression
}

\author{
João Anselmo Carolina M. Chaves \\ Department of Endocrinology and Nutrition, Hospital Divino Espírito Santo, Ponta Delgada, Portugal
}

\section{Keywords}

Resistance to thyroid hormone beta - Epigenetic regulation .

Deiodinase type 3 - Transgenerational inheritance

\begin{abstract}
Background: In previous publications, we have reported our findings demonstrating that exposure to high maternal levels of thyroid hormones (TH) has life-long effects on the wildtype (WT, without THRB mutation) progeny of mothers with resistance to thyroid hormone beta (RTH $\beta$ ). The mechanism of this epigenetic effect remains unclear. Objectives: We reviewed the mechanisms involved in the epigenetic regulation of TH target genes and understand how they may explain the reduced sensitivity to TH in the WT progeny of RTH $\beta$ mothers. Methods: The availability of a large, formerly genotyped Azorean population with many individuals harboring the THRB mutation, $\mathrm{R} 243 \mathrm{Q}$, provided us a model to study the influence of fetal exposure to high maternal TH levels. $\boldsymbol{R e}$ sults: The thyroid-stimulating hormone (TSH) response in WT adults was less suppressible following the administration of $\mathrm{L}$-triiodothyronine $\left(\mathrm{L}-\mathrm{T}_{3}\right)$. This finding suggests reduced sensitivity to TH that is induced by an epigenetic mechanism resulting from exposure to high maternal levels of $\mathrm{TH}$ during
\end{abstract}

pregnancy. The persistence of this effect across 3 generations of WT subjects favors transgenerational epigenetic inheritance. Based on preliminary studies in mice, we identified the naturally imprinted gene encoding deiodinase type 3 , i.e., DIO3, as a possible mediator of this epigenetic effect through increased inactivation of TH. Conclusion: Increased $\mathrm{D} 3$ expression and consequently increased $\mathrm{T}_{3}$ degradation appear to be responsible for the reduced sensitivity of the anterior pituitary to administered $\mathrm{L}_{\mathrm{T}}$. The imprinted $\mathrm{DIO}_{3}$ gene may be a candidate gene that mediates the epigenetic effect induced by exposure to high maternal levels of TH. However, we cannot exclude the role of other TH-responsive genes.

\footnotetext{
(c) 2020 European Thyroid Association Published by S. Karger AG, Basel
}

\section{Introduction}

The thyroid hormones $(\mathrm{TH})$, thyroxine $\left(\mathrm{T}_{4}\right)$ and triidodothyronine $\left(\mathrm{T}_{3}\right)$ are involved in multiple steps of growth, development, and differentiation. The importance of TH in human physiology is evident in children born with severe congenital hypothyroidism due to genetic defects or iodine deficiency. If left untreated, these
João Anselmo, MD

Department of Endocrinology and Nutrition, Hospital Divino Espirito Santo Ave D. Manuel I

PT-9500-317 Ponta Delgada, Azores (Portugal)

Joao_anselmo@sapo.pt 
children develop mental retardation and failure to thrive, resulting in a clinical condition known for centuries as cretinism [1]. Earlier in the past century, it was shown that adequate dietary intake of iodine could prevent endemic cretinism, and thyroid gland extracts were successfully used to treat hypothyroidism [2]. Thereafter, in 1986, TH receptors (TR) were mapped and identified as nuclear proteins binding preferentially to $\mathrm{T}_{3}[3]$. In the subsequent decades, it was demonstrated that TR are ubiquitously distributed in virtually all the cells of the organism, thereby linking extracellular signals to changes in the expression of numerous genes. In fact, studies on the cultures of cerebrocortical cells expressing around 15,000 genes, showed that $\mathrm{T}_{3}$ induced upregulation in 629 of these genes and downregulation in 526 of them [4]. A similar number of positively and negatively regulated genes were found in the liver after acute and chronic treatment with $\mathrm{T}_{3}$ [5]. Expression of TH-responsive genes first requires the presence of enough active hormone $\mathrm{T}_{3}$ within the cell. The principal and well-characterized effect of $\mathrm{TH}$ requires the translocation of the hormone into the nucleus where it interacts with TR to activate or repress the transcription of specific target genes. Although this is the mainstream mode of TH action, recent studies have provided evidence that alternative pathways that do not require direct interaction between TR and DNA may also play an important role. In fact, the expression of $\mathrm{TH}$ target genes can be modulated via epigenetic mechanisms, including histone modification, DNA methylation, and posttranscriptional silencing mediated by microRNA (miR).

The role of epigenetic events in gene expression was first reported by Waddington [6] in 1942; however, only during the last decades has the importance of epigenetic mechanisms gained much attention. Epigenetic events are defined as heritable changes in gene function that occur without modifications in the nucleotide sequence of DNA. Such events are therefore reversible but can persist throughout the entire life of the cell and may be transmitted to the next generation [7]. Epigenetic regulation of TH target genes is based on the modulation of the chromatin structure and accessibility to transcription factors achieved via several mechanisms [8]. One such mechanism is DNA methylation of cytosine residues at the $\mathrm{CpG}$ dinucleotide sequence. Transfer of methyl groups to these cytosine residues impairs the activity of promoters. Another is the posttranslational modification of histones by acetylation/deacetylation and methylation/demethylation that induces conformational changes in the tridimensional structure of this nu- clear protein. Specific histone modifications are associated with gene activation and silencing; furthermore, they regulate other chromatin remodeling events that control transcription. Finally, mirRs behave as generegulatory elements and are involved in various physiologic processes. They are known by their short length, i.e., around 22-23 nucleotides. They turn off gene expression by blocking translation or inactivating transcripts before translation. The relationship between the epigenetic mechanisms involved in the expression of $\mathrm{TH}$ target genes is summarized in Figure 1. Considering the mechanisms mentioned above, we discuss our findings in an epigenetic model of fetal hyperthyroidism due to exposure to high maternal levels of $\mathrm{TH}$ in mothers with resistance to thyroid hormone beta $(\mathrm{RTH} \beta)$. This dominantly inherited disorder is characterized by reduced responsiveness to $\mathrm{TH}$ caused by mutations of the THRB gene. Affected individuals are mostly asymptomatic despite high serum levels of free TH.

\section{Mechanisms of TH Action}

\section{Type 1 Mode of Action (Former Classic or Canonical} Pathways)

Although $\mathrm{T}_{4}$ is the predominant hormone produced by the thyroid gland, $\mathrm{T}_{3}$ exerts the majority of known $\mathrm{TH}$ effects at the tissue and cellular level, including hypothalamic and pituitary negative feedback regulation. $\mathrm{T}_{3}$ is mostly generated from the conversion of $\mathrm{T}_{4}$ in the extrathyroidal tissues via the activity of iodothyronine deiodinase type 1 (D1) and type 2 (D2). In contrast, deiodinase type 3 (D3) converts $\mathrm{T}_{3}$ and $\mathrm{T}_{4}$ to relatively inactive metabolites as reverse $\mathrm{T}_{3}\left(\mathrm{rT}_{3}\right)$ and $\mathrm{T}_{2}\left(3,3^{\prime}\right.$-diiodothyronine). Therefore, in addition to the changes in the production of $\mathrm{TH}$ by the thyroid gland, the availability of $\mathrm{T}_{3}$ in the tissues is also regulated by the intracellular activity of these enzymes [9]. The main pathway of TH action is at the genomic level via the regulating of gene expression by binding to the nuclear receptors of TH. TR belong to a superfamily of nuclear hormone receptors that act as ligand-regulated transcription factors. They bind $\mathrm{T}_{3}$ with about a 10-fold higher affinity than $\mathrm{T}_{4}$. Two genes encode for the 2 types of TR, namely THRA and THRB for TRa and $\mathrm{TR} \beta$, respectively. TR bind to TH-response elements (TRE) as either homodimers or heterodimers with retinoic $X$ receptors (RXR). In the absence of $\mathrm{T}_{3}$, unliganded TR interact with other molecules, most notably with transcriptional corepressors, such as silencing mediator of retinoic acid (SMRT) and nuclear corepressor-1 


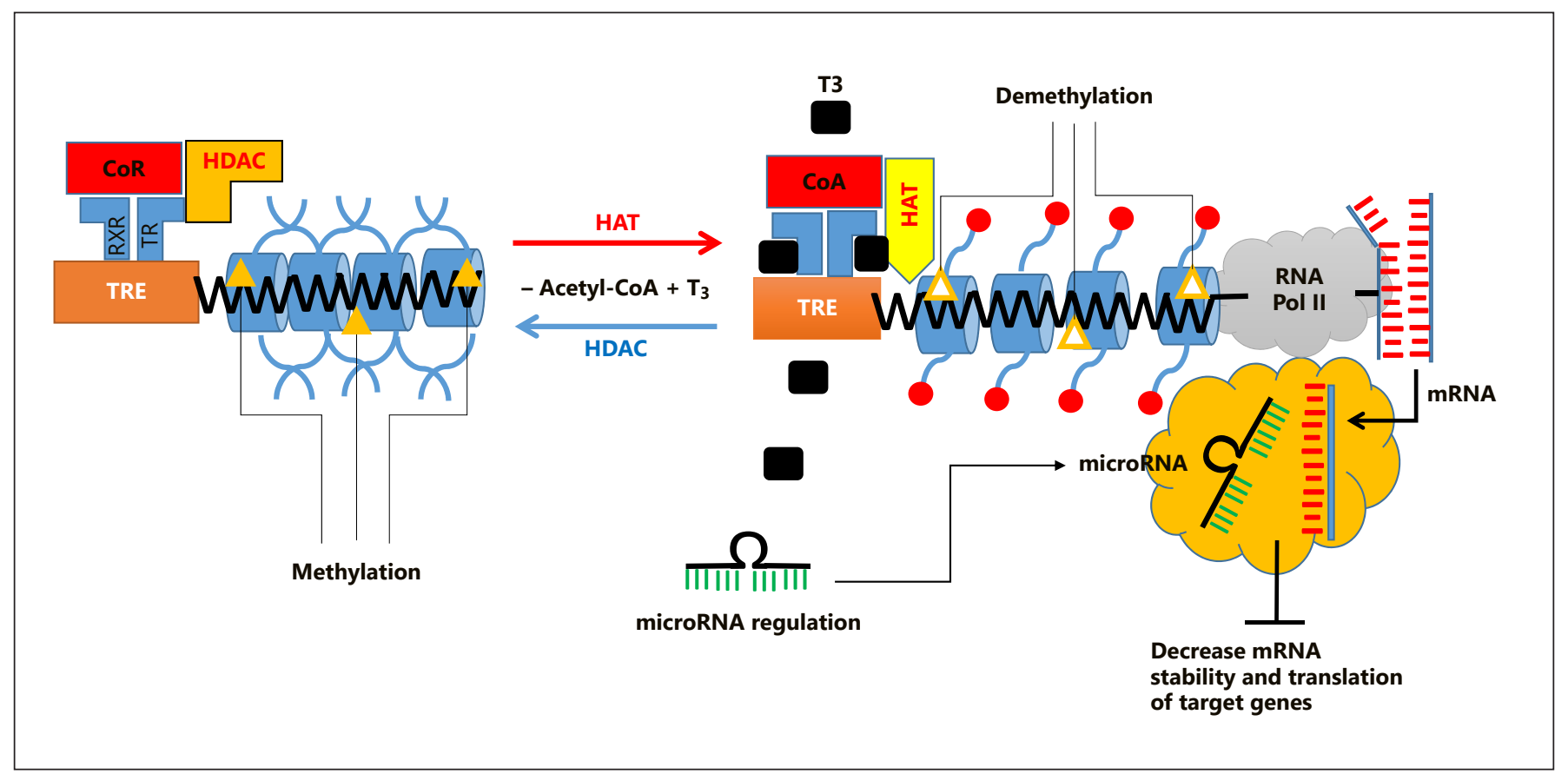

Fig. 1. In the absence of $T_{3}$, thyroid receptors (TR) form heterodimers with retinoic X receptor (RXR) and the complexes bind to the thyroid hormone (TH) response elements (TRE) in target genes to repress their expression. Binding of $\mathrm{T}_{3}$ to $\mathrm{TR}$ releases CoR (corepressors) and recruits coactivator complexes containing histone acetyltransferases (HAT). Acetyl groups from acetyl-CoA are add- ed by HAT onto the lysine residues of the histone tails, resulting in active chromatin, while the removal of acetyl residues by histone deacetylases (HDAC) results in the repression of chromatin. $\mathrm{T}_{3}$ regulates the levels of microRNA that block mRNA, leading to gene silencing. Methylation of DNA and histone is mostly associated with gene repression.

Table 1. Principal cofactors recruited by thyroid hormone receptors

\begin{tabular}{llll}
\hline Cofactors & Enzymatic activity & $\begin{array}{l}\text { Transcriptional } \\
\text { effect }\end{array}$ & Physiologic function \\
\hline $\begin{array}{l}\text { P160/SRC-1 } \\
\text { (steroid receptor coactivator) }\end{array}$ & acetylation (HAT) & activation & $\begin{array}{l}\text { male and female reproductive function; estrogen/ } \\
\text { progesterone balance }\end{array}$ \\
\hline $\begin{array}{l}\text { p300/CBP } \\
\text { (CREB-binding-protein) }\end{array}$ & acetylation (HAT) & activation & $\begin{array}{l}\text { G protein signaling; stimulates adenyl cyclase resulting } \\
\text { in cAMPC elevation }\end{array}$ \\
\hline $\begin{array}{l}\text { P/CAF } \\
\text { (CBP-associated factor) }\end{array}$ & acetylation (HAT) & activation & $\begin{array}{l}\text { activates p53 cascade and hepatocyte nuclear factor-1a } \\
\text { (HNF-1a); influences carbohydrate metabolism }\end{array}$ \\
\hline $\begin{array}{l}\text { CARM1 } \\
\text { (coactivator-associated arginine } \\
\text { methyltransferase) }\end{array}$ & methylation & activation & $\begin{array}{l}\text { regulates lipid metabolism via peroxisome } \\
\text { proliferator-activated receptor } \alpha \text { (PPAR })\end{array}$ \\
\hline $\begin{array}{l}\text { SUV39 } \\
\text { (suppressor of variegation 3-9 homolog) }\end{array}$ & histone methylation & repression & involved in silencing heterocromatin during cell division \\
\hline $\begin{array}{l}\text { G9a } \\
\text { (euchromatic histone methyltransferase) }\end{array}$ & histone methylation & repression & $\begin{array}{l}\text { transcriptional repression of developmental genes; } \\
\text { essential in early embryogenesis }\end{array}$ \\
\hline $\begin{array}{l}\text { HDAC (class I-IV) } \\
\text { SIRT1 (class III) }\end{array}$ & deacetylation via SIRT1 & repression & $\begin{array}{l}\text { downregulation of forkhead box O1 (FOXO1) increases } \\
\text { coactivator 1a (PGC-1a), stimulating adipogenesis }\end{array}$ \\
\hline $\begin{array}{l}\text { PRMT1 } \\
\text { (protein arginine N-methyltransferase 1) }\end{array}$ & histone methylation & activation & $\begin{array}{l}\text { methylated FOXO1 is retained in the nucleus, repressing } \\
\text { insulin and increasing gluconeogenesis }\end{array}$ \\
\hline
\end{tabular}

HAT, histone acetyltansferase; HDAC, histone deacetylase; SIRT1, nicotinamide adenine dinucleotide (NAD)-dependent deacetylase. 
(NCoR1), suppressing the expression of the genes positively regulated by $\mathrm{T}_{3}$ [10]. Upon ligand binding, TR undergoes a conformational change, attracting a new set of activator proteins, such as SRC-1 (p160/steroid receptor coactivator 1) and histone acetyltransferase (Table 1). Activation of theses enzymes induces modifications in the tridimensional structure of histones, particularly around the target gene promoters fostering the activity of RNA polymerases. In contrast to positively regulated genes, certain genes are negatively regulated by $\mathrm{T}_{3}$. This is the case with the thyrotropin/thyroid-stimulating hormone (TSH) gene, critical for the feedback control of the $\mathrm{TH}$ axis. The TSH gene is downregulated by $\mathrm{T}_{3}$ and overexpressed during $\mathrm{T}_{3}$ deprivation. The mechanism of $\mathrm{T}_{3^{-}}$ negative regulation is less well understood [11]. It may result from direct DNA binding of TR to TRE with repressor activity. But, irrespective of the mechanism, what seems clear is that unliganded TR, instead of operating as inactive, passive agents, repress gene expression. Therefore, it was not surprising that the targeted deletion of TR $\alpha$ and TR $\beta$ in mice failed to reproduce the effects of TH depletion.

\section{Type 2-4 Modes of Action (Former Nongenomic \\ Pathways)}

While nuclear receptors of TH have proven useful for understanding the transcriptional changes on $\mathrm{TH}$ target genes, there is compelling evidence that several other mechanisms may also play a role. In fact, many actions of TH may occur too quickly to be mediated by enhanced or repressed target gene expression [12]. In addition, $\mathrm{T}_{4}$ can be more potent than $\mathrm{T}_{3}$ for some of these effects. Furthermore, increasing evidence shows that $\mathrm{T}_{4}$ can directly modulate gene expression, depending on the TR subtype and other cellular cofactors. Together, these alternative mechanisms have been known as "nongenomic pathways" of TH action, an inaccurate designation. Expression of target genes can, in fact, be changed in response to TH without TR binding to DNA. Moreover, the direct action of $\mathrm{T}_{3}$ in the mitochondria via 2 truncated TRa1 isoforms (p28-p43) is not necessarily extragenomic, because the existence of a mitochondrial genome is well established [11]. Finally, changes in the expression of $\mathrm{TH}$ target genes may be quickly induced by $\mathrm{TH}$ through histone modification that facilitates the activity of transcription factors and RNA polymerases. In order to encompass the diversity of the mechanisms involved in $\mathrm{TH}$ signaling, a more precise nomenclature was recently formulated that takes into consideration 4 types of cellular responses to $\mathrm{TH}$ [13]. Type 1, the canonical pathway, re-

Epigenetic Regulation of TH Target Genes quires DNA binding to mediate the genomic response to TH. In the type 2 mode of action, TR do not bind directly to DNA and tether into DNA by protein-protein interactions that mediate the crosstalk with other transcriptional factors around genomic specific localizations. Type 3 responses are elicited by TR binding to cytosolic proteins, including regulatory proteins as the $\mathrm{p} 85$ regulatory subunit of phosphatidylinositol 3-kinase (PI3K). This, in turn, initiates intracellular responses that culminate in the expression of several target genes like those involved in glucose metabolism. Finally, type 4 responses can be triggered by the binding of $\mathrm{TH}$, and preferentially $\mathrm{T}_{4}$, to a membrane protein called integrin [14]. These actions initiated at the plasma membrane induce the expression of the genes that affect angiogenesis and cell proliferation via activation of the mitogen-activated protein kinase (MAPK) signaling cascade. Integrin $\alpha v \beta 3$ is structurally unrelated and has no sequence homology with TR. Therefore, it is not a "receptor" in the classic sense, and this designation should be avoided. Although this 4-way model provides a broad explanation of $\mathrm{TH}$ action, it should be noted that the same stimulus may act through multiple mechanisms and some of these are coupled. Furthermore, epigenetic regulatory mechanisms may be required to bring transcriptional factors into close spatial proximity with the $\mathrm{TH}$ target genes.

\section{Epigenetic Regulation of TH Target Genes}

Short and Long-Term Effects of Fetal Hyperthyroidism

During the last 2 decades, we have studied an extended family, with RTH $\beta$ harboring a dominantly inherited mutation of THRB which leads to substitution of Arg243 $\rightarrow$ Gln (R243Q) [15]. The mutant TR binds normally to $\mathrm{T}_{3}$, but, once bound to DNA, the dissociation of the homodimers and corepressors is markedly impaired [16]. This suggests that the receptor DNA-binding domain can modulate the function of the hormone-binding domain via allosteric mechanisms. On the other hand, $\mathrm{RTH} \beta$ patients are, in the majority of cases, heterozygous for mutations in the THRB gene, suggesting that the pathogenesis of the disease is driven by dominant negative inhibition of wild-type (WT) TR $\beta$. Thus, the mutant $\operatorname{TR} \beta$ does not act by reducing the amount of a functional $\operatorname{TR} \beta$ (haploinsufficiency) but by interfering with the function of the WT TR $\beta$ (a dominant negative effect). The resulting insensitivity to $\mathrm{TH}$ due to the genetic defect of the TR $\beta$ is, most of the time, entirely compensated by an overactive thyroid gland which is stimulated by TSH with 
Table 2. Increase in body weight and evolution of thyroid function during the first year of life in a wild-type infant born to a mother with RTH $\beta$

\begin{tabular}{|c|c|c|c|c|c|c|c|c|c|}
\hline & $\begin{array}{l}\text { Term pregnancy }{ }^{1} \\
\text { (cord blood) }\end{array}$ & 1 week & 4 weeks & 6 weeks & 10 weeks & 4 months & 6 months & 8 months & 1 year \\
\hline Weight, kg & 2.240 & 2.160 & 3.160 & 3.490 & 4.060 & 5.100 & 6.400 & 7.450 & 8.740 \\
\hline $\operatorname{SDS}^{\circ}$ & -2.178 & & -2.36 & -1.88 & -1.8 & -1.816 & -1.293 & -0.978 & -0.95 \\
\hline TSH, 0.4-3.8 mIU/L & $<0.1$ & $<0.1$ & $<0.1$ & 0.2 & 0.6 & 0.9 & 1.68 & 2.76 & 1.88 \\
\hline Free $\mathrm{T}_{4}, 0.7-1.6 \mu \mathrm{g} / \mathrm{dL}$ & 1.58 & 1.02 & 0.63 & 1.24 & 1.41 & 1.39 & 1.33 & 1.27 & 1.18 \\
\hline $\mathrm{L}-\mathrm{T}_{4}, \mu \mathrm{g} /$ day & & - & 50 & 50 & 50 & 50 & 50 & 50 & - \\
\hline
\end{tabular}

RTH $\beta$, resistance to thyroid hormone beta; SDS, standard deviation score; TSH, thyroid-stimulating hormone/thyrotropin; $\mathrm{L}_{-} \mathrm{T}_{4}$, levothyroxine.

${ }^{1}$ Taken at 39 weeks.

augmented biologic potency. Consequently, the serum levels of free TH are persistently increased. Fertility was not impaired in the affected couples regardless of whether women or men harbored the mutant THRB. Therefore, the availability of several generations of descendants to affected RTH $\beta$ mothers provided us with a model to investigate the effect of exposure to high $\mathrm{TH}$ levels during fetal life. Women harboring the THRB mutation had a significantly higher rate of miscarriage than those whose spouses were affected. Data obtained from children born to an affected parent show that only WT infants born to mothers with RTH $\beta$ present with a low birth weight. RTH $\beta$ mothers with lower TH levels due to prior ablative treatment of the thyroid gland give birth to WT infants of normal weight and nonsuppressed TSH. The same result was obtained by administering antithyroid medication to the affected mothers carrying a WT fetus [17].

In conclusion, these findings suggest that high maternal TH levels could induce a catabolic state during fetal life, similar to what happens in children and adults with uncontrolled hyperthyroidism. Mothers with RTH $\beta$ were not thyrotoxic and had no thyroid autoantibodies; we can thus conclude that the miscarriages and hyperthyroid features were the consequences of fetal hyperthyroidism. The main reason that high maternal TH levels affect only the WT progeny (without THRB gene mutation) of RTH $\beta$ mothers, is because, like their mothers, the fetuses harboring the mutation are protected from the toxic effects of TH due to the reduced effectiveness of TR $\beta$. Table 2 illustrates the increase of body weight and thyroid function in a WT child born to an RTH $\beta$ mother. It shows that intrauterine exposure to high maternal levels of $\mathrm{TH}$ caused fetal and neonatal hyperthyroidism. After birth, there was a sharp decline in the serum levels of free $\mathrm{T}_{4}$. However, the recovery of the infant hypothalamic-pituitary-thyroid (HPT) axis took about 8 months. During this time, the child was supplemented with $\mathrm{L}-\mathrm{T}_{4}$ to prevent neurodevelopmental constraints due to central hypothyroidism. Given the long-lasting effect of fetal hyperthyroidism in TSH suppression, we were unsure whether the abnormalities in the regulation of TSH secretion persist into adulthood.

To study the functionality of the HPT axis in WT adults born to affected mothers, we evaluated the sensitivity to $\mathrm{TH}$ with the use of a standard sensitive test that measures the TSH response to thyroid-releasing hormone (TRH) after the administration of the biologically active $\mathrm{L}_{-} \mathrm{T}_{3}$. The TSH response to TRH was found to be less suppressible when $\mathrm{L}-\mathrm{T}_{3}$ in WT adults born to a mother with high TH levels [18]. In contrast, the progeny of fathers with RTH $\beta$ did not display these consequences as their unaffected mothers had normal TH levels. This finding is consistent with that for reduced sensitivity to $\mathrm{TH}$, suggesting that fetal hyperthyroidism causes lifelong effects on the feedback regulation of the HPT axis.

To further investigate the mechanism of reduced sensitivity to TH in WT adults born to mothers with RTH $\beta$, we studied a mouse model where TH levels were of the same magnitude as in humans who have the R243Q mutation of THRB. As in humans, mice born to dams with $\mathrm{RTH} \beta$ also exhibited a reduced sensitivity to $\mathrm{L}-\mathrm{T}_{3}$ compared to those born to fathers with RTH $\beta$. Their pituitary showed a significantly higher level of D3 mRNA [18]. D3 is a TH-inactivating enzyme that is usually expressed during fetal life. It is known to convert $\mathrm{T}_{4}$ and $\mathrm{T}_{3}$ into $\mathrm{rT}_{3}$ and $\mathrm{T}_{2}$, respectively. Therefore, increased D3 expression and, consequently, increased $\mathrm{T}_{3}$ degradation seem to provide a more likely explanation for the reduced sensitivity of the anterior pituitary to administered L-T3. This observation provided a putative mechanism for the development of reduced sensitivity to $\mathrm{TH}$ via local reduction of TH-mediated feedback suppression of TSH. 


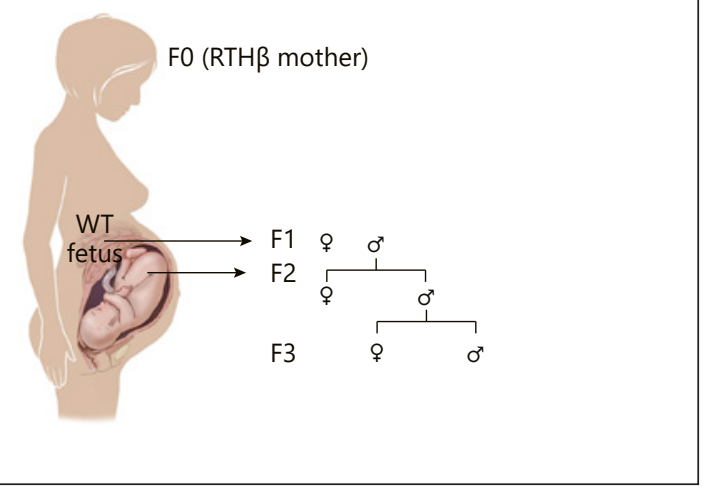

Fig. 2. Reduced sensitivity to thyroid hormones (TH) is an epigenetic phenomenon transmitted along male line. F0 is the pregnant RTH $\beta$ mother. The wild-type (WT) embryo (F1) is directly exposed to high maternal levels of TH. This is also true for the developing germ cell lines in the testicles (male transmission) which may also affect the F2 generation (i.e., the grandmother's influence). The F3 generation is therefore the first generation that has not been exposed to high levels of TH.

Epigenetic Transmission of Reduced Sensitivity to TH

We followed the inheritance of this epigenetic phenomenon by studying 3 generations of WT adults descended from affected mothers whose parents and grandparents were not exposed to high levels of TH. Tests of TH sensitivity were repeated in adult WT individuals belonging to each of these generations. Reduced sensitivity to $\mathrm{TH}$ was documented in the subsequent generations of WT individuals descended from fathers but not from mothers with reduced sensitivity to TH [19]. Therefore, the phenotype persisted over 3 generations and was transmitted down the male line. Since the effect of intrauterine total body and gonadal exposure to elevated $\mathrm{TH}$ can potentially affect only the first (F1) and second (F2) generations, respectively, the results obtained from the third generation (F3) confirmed a true inheritance of the epigenetic effect (Fig. 2). This finding favors a transgenerational epigenetic inheritance which has been rarely documented in humans.

\section{The DIO3 Gene as a Candidate Gene}

The mechanism of the transmission of this epigenetic phenomenon remains poorly clarified. It would require incomplete erasure of the parental epigenetic marks in the gametes to allow the transmission of the phenotype over multiple generations. This is known to occur in imprinted genes, such as the gene encoding D3, i.e., DIO3, which is predominantly expressed from the paternal allele, particularly in the central nervous system (CNS)
[20]. Thus, the imprinted DIO3 appears a suitable candidate to mediate the transgenerational transmission of reduced sensitivity to TH along the male line. This effect may be mediated by a cell-specific increase of DIO3 expression. Overexpression of $\mathrm{DIO} 3$ could be the explanation for our finding of increased levels of D3 mRNA in the pituitaries of WT mice born to affected dams. DIO3 function is to inactivate $\mathrm{TH}$, and it thus regulates the tissue-specific local availability of active $\mathrm{TH}$. The absence of D3 expression, as observed in DIO3 $\mathrm{KO}$ mice, resulted in severe thyrotoxicosis in perinatal life, leading to central hypothyroidism due to the suppression of the HPT axis [21]. Finally, DIO3 transcription, particularly in the CNS, is highly sensitive to local hypoxic conditions and to the $\mathrm{TH}$ state, functioning as a negative feedback loop in response to increased levels of $\mathrm{TH}$ [22]. The question is: How is the effect of fetal hyperthyroidism in the DIO3 gene maintained throughout an entire life and over several generations?

\section{Epigenetic Mechanisms}

Methylation

Methylation is known to produce stable and persistent epigenetic markers. Genomic imprinting is associated with a differential methylation (imprint) between parental alleles in key regulatory sequences. The presence of methylcytosine in gene promoters and enhancers inactivates their transcription via 2 mechanisms [23]. First, the methylation of DNA itself may physically impede the binding of the transcriptional proteins to the gene. In the second, and probably more important mechanism, the methylated DNA may be bound by proteins known as methyl-CpG-binding domain (MBD) proteins. MBD proteins then recruit additional proteins to the locus, such as histone deacetylase and other chromatin-remodeling proteins that can modify histone, making DNA less accessible to transcription factors. For example, the expression of the sodium iodide symporter gene (SLC5A5), responsible for the uptake of iodine in the thyroid, was shown to be regulated by cytosine methylation of its promoter [24]. Therefore, in general, DNA methylation is associated with gene repression, while DNA demethylation promotes gene activation.

TR regulates the transcription of the gene encoding de novo DNA methyltransferase (DNMT3a). The expression of DNMT3a can be induced by exogenous $\mathrm{T}_{3}$ administration. Thus, exposure to high levels of TH may increase the methylation of susceptible sequences of DNA, particularly the $\mathrm{CpG}$ dinucleotide sequence. Imprinted genes, such as DIO3, are expressed in a parent-of-origin-specific man- 
Fig. 3. The imprinting control region of the gene encoding deiodinase type 3 (DIO3) contains multiple DNA sequences called insulators, which bind the transcriptional repressor CCCTC-binding factor (CTCF). The insulators are methylated when paternally inherited and unmethylated when derived from the mother. CTCF can only bind to unmethylated sequences of maternal origin. Binding of CTCF to insulators leads to chromatin loop formation in a manner that blocks communication between the enhancer and the promoter of DIO3, repressing its expression.

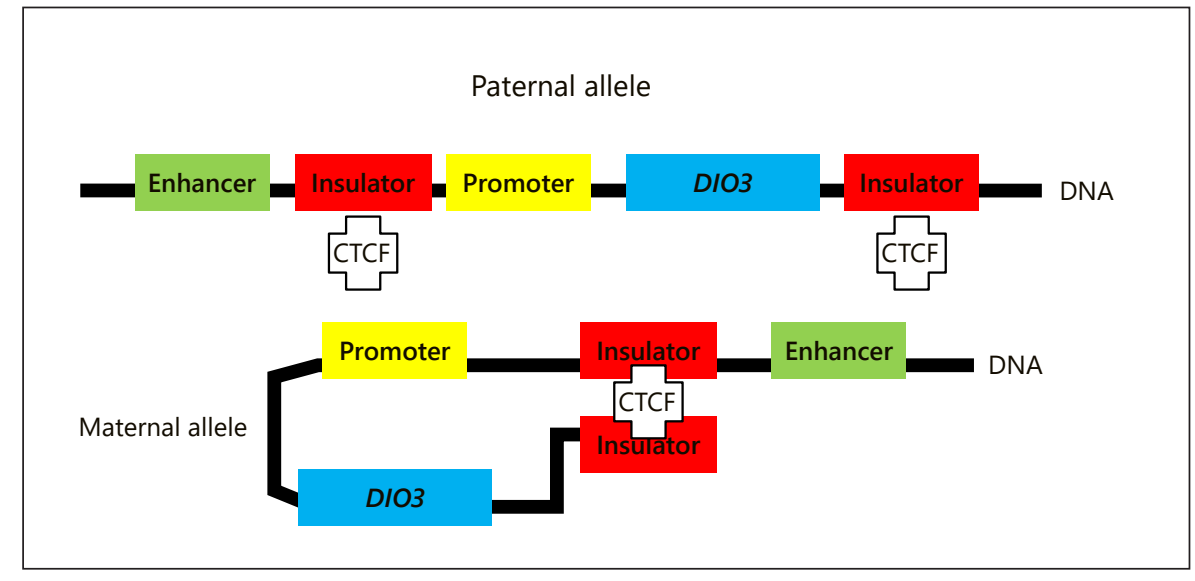

ner controlled by allele-specific DNA methylation marks established in the gametes. They are frequently organized in clusters in the genome, and several imprinted clusters harbor CCCTC-binding factor (CTCF)-dependent insulators involved in the regulation of monoallelic expression. Insulators are short nucleotide sequences of DNA that establish connections between promoters and enhancers of the gene. When CTCF, an $82-\mathrm{kDa}$ protein with 11 zinc fingers, binds to an insulator sequence, the crosstalk between the enhancer and the gene promoter is hampered and transcription of the gene is blocked (Fig. 3). In this sense, methylation of the imprinting control region enhances DIO3 expression of the paternal allele by preventing gene repression via insulator-binding [25]. It is still not clear why the insulators of the maternal allele of DIO3 gene are less susceptible to methylation. Interestingly, the promoters and enhancers of both alleles of $\mathrm{DIO} 3$ are relatively resistant to methylation. In conclusion, DNA methylation is an active and efficient epigenetic mechanism of $\mathrm{TH}$ target gene regulation.

\section{Histone Modifications}

The expression of $\mathrm{TH}$ targeted genes in response to methylation is also mediated by histone modifications. TR is known to recruit several complexes of cofactors containing enzymes. Histone modifications therefore play an important role in $\mathrm{TH}$ signaling. The best-studied histone modifications are acetylation and methylation. Histone acetyltransferases regulate gene activation by adding acetyl groups to the histone which leads to a change in the net positive charge of histone tails, thereby facilitating exposure of DNA to the transcriptional machinery [18] (Fig. 1). In contrast, histone deacetylases remove the acetyl group, tying the DNA around the histone [26]; this activity is as- sociated with gene silencing. The balance between the 2 processes, together with other proteins and DNA modifications such as DNA methylation, regulates chromatin accessibility and gene expression. Methylation is another well-known mechanism of histone modification. Histone methyltransferases and histone demethylases are examples of enzymes with a strong impact on TH targeted gene regulation. For instance, the downregulation of the TRH gene by the $\mathrm{T}_{3} / \mathrm{TR} \beta$ complex involves the acetylation and methylation of specific residues of histone tails around the $\mathrm{TRH}$ promoter region of the gene. Other mechanisms of histone modification, such as ubiquitylation and sumoylation, can also modulate $\mathrm{TH}$ actions.

\section{MicroRNAs}

miRs are involved in another mechanism of epigenetic regulation of the TH targeted genes. $\mathrm{TH}$ is shown to regulate the levels of miR-206/miR-133b in human skeletal muscles, miR208a in the heart, and miR21 and miR181d in the liver [27]. In a mouse model of myocardial infarction, Dio3 is upregulated in cardiomyocytes to create a local hypothyroid condition to increase the regenerative capacity by switching to the fetal gene program. Dio3 seems to be the target of miR-214. Given that miR-214 is negatively regulated by $\mathrm{TH}$, it can be hypothesized that miR-214 and Dio3 form a negative feedback loop in cardiomyocytes and perhaps in several other tissues, including the pituitary tissue. In conclusion, miRs are newly recognized mediators of $\mathrm{TH}$ target gene expression regulation at a posttranscriptional level.

Epigenetic modification is also required for the T3dependent activation of sarcoplasmic reticulum $\mathrm{Ca}^{+}$ ATPase (SERCA2a) [28]. SERCA2a is responsible for intracellular calcium $\left(\mathrm{Ca}^{2+}\right)$ homeostasis and contractility 
Table 3. Epigenetic regulation of the thyroid hormone $(\mathrm{TH})$ target genes with a broad metabolic impact

\begin{tabular}{|c|c|c|c|}
\hline Physiologic process & Gene involved & Epigenetic mechanism & $\begin{array}{l}\text { TH-mediated effect on } \\
\text { target genes }\end{array}$ \\
\hline Free radical scavenger & superoxide dismutase gene (SOD2) & $\begin{array}{l}\text { miR-222; miR-31; miR-155 } \\
\text { deacetylation SIRT1-dependent }\end{array}$ & $\begin{array}{l}\text { gene silencing } \\
\text { increases transcription }\end{array}$ \\
\hline $\begin{array}{l}\text { Mitochondrial biogenesis, } \\
\text { thermogenesis, and } \\
\text { mitophagy }\end{array}$ & $\begin{array}{l}\text { peroxisome proliferator coactivator } \\
1-\alpha(P G C 1 \alpha) \\
\text { mitochondrial transcription factor } \\
\text { A }(T F A M) \\
\text { Unc-51-like autophagy-activating } \\
\text { kinase (ULK1) }\end{array}$ & $\begin{array}{l}\text { posttranslational activation via SIRT1 } \\
\text { of PGC-1 } \alpha \text {, estrogen receptor-related } \alpha \\
(\text { ESRR } \alpha \text { ) and peroxisome proliferator- } \\
\text { activated receptor gamma (PPAR } \gamma)\end{array}$ & increases transcription \\
\hline $\begin{array}{l}\text { Fatty acid oxidation and } \\
\text { cholesterol absorption } \\
\text { in the intestine }\end{array}$ & $\begin{array}{l}\text { carnitine O-palmitoyl transferase } 2 \text {, } \\
\text { mitochondrial (CPT2) } \\
\text { sterol O-acyltransferase } 2 \text { (SOAT2) }\end{array}$ & $\begin{array}{l}\text { posttranslational activation of PGC-1a } \\
\text { and ESRR } \alpha \text { via SIRT1; miR-222; } \\
\text { miR-31; miR-155; miR-181 }\end{array}$ & gene silencing \\
\hline $\begin{array}{l}\text { Cell cycle } \\
\text { DNA repair and apoptosis }\end{array}$ & tumor suppressor gene (P53) & $\begin{array}{l}\text { miR-30; miR-144/499 deacetylation } \\
\text { SIRT1-dependent }\end{array}$ & $\begin{array}{l}\text { gene silencing; } \\
\text { tumor growth }\end{array}$ \\
\hline
\end{tabular}

miR, microRNAs; SIRT, nicotinamide adenine dinucleotide (NAD)-dependent deacetylase; SERCA2, sarcoplasmic reticulum Ca ${ }^{2+}$ ATPase.

of the heart. SERCA2 removes $\mathrm{Ca}^{2+}$ from the cytosol and stores it in the sarcoplasmic reticulum, leading to diastolic relaxation. Expression of SERCA2 is largely dependent on direct regulation by $\mathrm{T}_{3}$ as well as by the inhibition of its counterpart phospholamban (PLB) [29]. The expression of the gene encoding SERCA2 is positively regulated by $\mathrm{TH}$ and could be increased with $\mathrm{T}_{3}$ treatment. In contrast, PLB is negatively regulated by $\mathrm{T}_{3}$. Thus, $\mathrm{T}_{3}$ is able to relax the heart and enhance cardiac output by reducing the amount of cytosolic $\mathrm{Ca}^{2+}$ by increasing SERCA2 expression. Furthermore, the cardiac myocytes contain myosin heavy chain (MHC) $\alpha$ and MHC $\beta$, that are positively and negatively regulated by $\mathrm{T} 3$, respectively.

Finally, sirtuin-mediated epigenetic mechanisms are also involved the regulation of TH target genes [30]. SIRT1 (the first of 7 different sirtuin enzymes) is a nicotinamide adenine dinucleotide (NAD)-dependent deacetylase that removes the acetyl groups from proteins, such as histones, thereby affecting the expression of TH target genes. The deacetylation of histone is associated with gene repression and requires $\mathrm{NAD}^{+}$. Therefore, the activity of SIRT1 is connected to the ratio $\mathrm{NAD}^{+} / \mathrm{NADH}$ that reflects the metabolic status of the cell. SIRT1 and TR $\beta 1$ were found to physically interact with each other and SIRT1 enhances the TH-responsiveness in hepatic cells. The SIRT1-TR $\beta 1$ interaction may be protective for reducing $\mathrm{TH}$-mediated transcriptional activation when general transcription needs to be reduced during times of nutrient or energy stress. In conclusion, SIRT1 is a gene-specific TR $\beta 1$ coregulator, and the TR $\beta 1 /$ SIRT1 interaction could play an important role in the regulation of the liver metabolic response. The physiologic relevance of the negative regulation of SIRT1 by TH remains unclear. In Table 3, we summarize the epigenetic regulation of some of the TH-responsive genes that have a broad metabolic impact.

\section{Conclusion}

Our findings in the progeny of RTH $\beta$ mothers provide evidence that exposure to high maternal levels of TH not only have direct toxic effects on the fetus, but also cause permanent reduced sensitivity to TH. The short- and longterm effects were both only found in WT individuals (without THRB mutations) born to affected mothers. While the exact mechanism underlying the reduced sensitivity to $\mathrm{TH}$ remains unknown, it correlates with the $\mathrm{D} 3$ overexpression demonstrated in the pituitary glands of mice born to dams with a high TH. This enzyme inactivates TH and is encoded by an imprinted gene with specific parent of origin. 
DIO3 plays a critical role in protecting the neurons from excess $\mathrm{TH}$, particularly during uterine life. Therefore, in the WT progeny of affected mothers, the upregulation of DIO3 during pregnancy seems to be a physiologic adaptation to the high maternal levels of TH. However, the persistence of reduced sensitivity to $\mathrm{TH}$ in $\mathrm{WT}$ adults born to affected mothers, and its transmission over 3 generations is an epigenetic phenomenon persisting way beyond the initial stimulus. The exact mechanism underlying transgenerational inheritance of this epigenetic effect remains unclear. It is also unclear whether reduced sensitivity to $\mathrm{TH}$ is restricted to the thyrotrophs or also affects other cells and tissues. Finally, we are unsure whether the mechanism of refractoriness to TH in patients without THRB is not a consequence of the epigenetic modulation of TH target genes in response to environmental conditions, similar to that induced by the exposure to high maternal levels of TH. In conclusion, understanding the epigenetic mechanisms involved in the regulation of TH-responsive genes could reveal the role they play in the expression of genetic susceptibility to thyroid disorders, in particular autoimmune diseases and cancer. It may also help the diagnosis and development of targeted therapies.

\section{Acknowledgment}

We thank Professor Samuel Refetoff of the University of Chicago, IL, USA, who provided insight and expertise and greatly assisted with the research reported in this article. We also thank authors of previous published articles whose collaboration was indispensable to this work.

\section{Disclosure Statement}

The authors have no conflicts of interest to declare.

\section{Funding Source}

There was no significant financial support for this work that could have influenced the outcome.

\section{Author Contributions}

J.A. conceived and wrote the manuscript. C.M.C. revised the manuscript for important intellectual content. Both authors reviewed and approved the final manuscript.

\section{References}

1 Salisbury S. Cretinism: the past, present and future of diagnosis and cure. Paediatr Child Health. 2003 Feb;8(2):105-6.

2 Delange $F$. The disorders induced by iodine deficiency. Thyroid. 1994;4(1):107-28.

3 Usala SJ, Bale AE, Gesundheit N, Weinberger C, Lash RW, Wondisford FE, et al. Tight linkage between the syndrome of generalized thyroid hormone resistance and the human $\mathrm{c}$ erbA beta gene. Mol Endocrinol. 1988 Dec; 2(12):1217-20.

4 Gil-Ibañez P, García-García F, Dopazo J, Bernal J, Morte B. Global transcriptome analysis of primary cerebrocortical cells: identification of genes regulated by triiodothyronine in specific cell types. Cereb Cortex. 2017 Jan;27(1): 706-17.

5 Ohba K, Leow MK, Singh BK, Sinha RA, Lesmana R, Liao XH, et al. Desensitization and Incomplete Recovery of Hepatic Target Genes After Chronic Thyroid Hormone Treatment and Withdrawal in Male Adult Mice. Endocrinology. 2016 Apr;157(4):1660 72.

6 Villota-Salazar NA, Mendoza-Mendoza A, González-Prieto JM. Epigenetics: from the past to the present. Front Life Sci. 2016 Dec; 9(4):347-70.

7 Allis CD, Jenuwein T. The molecular hallmarks of epigenetic control. Nat Rev Genet. 2016 Aug;17(8):487-500.
8 Forini F, Nicolini G, Pitto L, Iervasi G. Novel Insight into the Epigenetic and Post-transcriptional Control of Cardiac Gene Expression by Thyroid Hormone. Front Endocrinol (Lausanne). 2019 Aug;10:601.

9 Mendoza A, Hollenberg AN. New insights into thyroid hormone action. Pharmacol Ther. 2017 May;173:135-45.

10 Cheng SY, Leonard JL, Davis PJ. Molecular aspects of thyroid hormone actions. Endocr Rev. 2010 Apr;31(2):139-70.

11 Chiamolera MI, Wondisford FE. Minireview: thyrotropin-releasing hormone and the thyroid hormone feedback mechanism. Endocrinology. 2009 Mar; 150(3):1091-6.

12 Hiroi Y, Kim HH, Ying H, Furuya F, Huang $\mathrm{Z}$, Simoncini $\mathrm{T}$, et al. Rapid nongenomic actions of thyroid hormone. Proc Natl Acad Sci USA. 2006 Sep;103(38):14104-9.

13 Flamant F, Cheng SY, Hollenberg AN, Moeller LC, Samarut J, Wondisford FE, et al. Thyroid hormone signaling pathways: time for a more precise nomenclature. Endocrinology. 2017 Jul;158(7):2052-7.

14 Davis PJ, Davis FB, Cody V. Membrane receptors mediating thyroid hormone action. Trends Endocrinol Metab. 2005 Nov;16(9):429-35.

15 Anselmo J, Cao D, Karrison T, Weiss RE, Refetoff S. Fetal loss associated with excess thyroid hormone exposure. JAMA. 2004 Aug; 292(6):691-5.
16 Yagi H, Pohlenz J, Hayashi Y, Sakurai A, Refetoff S. Resistance to thyroid hormone caused by two mutant thyroid hormone receptors beta, R243Q and R243W, with marked impairment of function that cannot be explained by altered in vitro 3,5,3'-triiodothyroinine binding affinity. J Clin Endocrinol Metab. 1997 May;82(5):1608-14.

17 Pappa T, Anselmo J, Mamanasiri S, Dumitrescu AM, Weiss RE, Refetoff S. Prenatal diagnosis of resistance to thyroid hormone and its clinical implications. J Clin Endocrinol Metab. 2017 Oct;102(10):3775-82.

18 Srichomkwun P, Anselmo J, Liao XH, Hönes GS, Moeller LC, Alonso-Sampedro M, et al. Fetal Exposure to High Maternal Thyroid Hormone Levels Causes Central Resistance to Thyroid Hormone in Adult Humans and Mice. J Clin Endocrinol Metab. 2017 Sep; 102(9):3234-40.

19 Anselmo J, Scherberg N, Dumitrescu A, Refetoff S. Reduced sensitivity to thyroid hormone as an epigenetic marker transmitted along male line. Thyroid. 2019 Jun;298(6): 778-82.

20 Martinez ME, Cox DF, Youth BP, Hernandez A. Genomic imprinting of DIO3, a candidate gene for the syndrome associated with human uniparental disomy of chromosome 14. Eur J Hum Genet. 2016 Nov; 24(11):1617-21. 
21 Hernandez A, Martinez ME, Liao XH, Van Sande J, Refetoff S, Galton VA, et al. Type 3 deiodinase deficiency results in functional abnormalities at multiple levels of the thyroid axis. Endocrinology. 2007 Dec;148(12):5680-7.

22 Simonides WS, Mulcahey MA, Redout EM, Muller A, Zuidwijk MJ, Visser TJ, et al. Hypoxia-inducible factor induces local thyroid hormone inactivation during hypoxic-ischemic disease in rats. J Clin Invest. 2008 Mar; 118(3):975-83.

23 Lee DY, Teyssier C, Strahl BD, Stallcup MR. Role of protein methylation in regulation of transcription. Endocr Rev. 2005 Apr;26(2): $147-70$.

24 Dohán O, De la Vieja A, Paroder V, Riedel C, Artani M, Reed M, et al. The sodium/iodide Symporter (NIS): characterization, regulation, and medical significance. Endocr Rev. 2003 Feb;24(1):48-77.
25 Charalambous M, Hernandez A. Genomic imprinting of the type 3 thyroid hormone deiodinase gene: regulation and developmental implications. Biochim Biophys Acta. 2013 Jul; 1830(7):3946-55.

26 Lee KC, Li J, Cole PA, Wong J, Kraus WL. Transcriptional activation by thyroid hormone receptor-beta involves chromatin remodeling, histone acetylation, and synergistic stimulation by p300 and steroid receptor coactivators. Mol Endocrinol. 2003 May; 17(5): 908-22.

27 Zhang D, Li Y, Liu S, Wang YC, Guo F, Zhai $\mathrm{Q}$, et al. microRNA and thyroid hormone signaling in cardiac and skeletal muscle. Cell Biosci. 2017 Mar;7(1):14-25.
28 Inesi G, Prasad AM, Pilankatta R. The Ca2+ ATPase of cardiac sarcoplasmic reticulum: physiological role and relevance to diseases. Biochem Biophys Res Commun. 2008 Apr; 369(1):182-7.

29 Belakavadi M, Saunders J, Weisleder N, Raghava PS, Fondell JD. Repression of cardiac phospholamban gene expression is mediated by thyroid hormone receptor- $\{\alpha\} 1$ and involves targeted covalent histone modifications. Endocrinology. 2010 Jun;151(6):294656.

30 Zhang T, Kraus WL. SIRT1-dependent regulation of chromatin and transcription: linking $\mathrm{NAD}(+)$ metabolism and signaling to the control of cellular functions. Biochim Biophys Acta. 2010 Aug;1804(8):1666-75. 